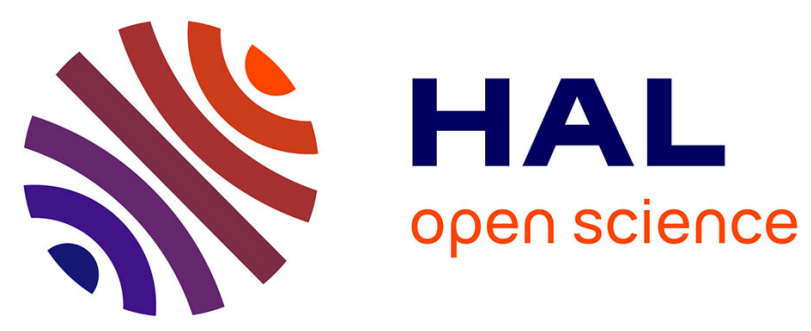

\title{
Galvanic corrosion between zinc and carbon steel investigated by local electrochemical impedance spectroscopy
}

Maixent Mouanga, Monique Puiggali, Bernard Tribollet, Vincent Vivier, Nadine Pébère, Olivier Devos

\section{To cite this version:}

Maixent Mouanga, Monique Puiggali, Bernard Tribollet, Vincent Vivier, Nadine Pébère, et al.. Galvanic corrosion between zinc and carbon steel investigated by local electrochemical impedance spectroscopy. Electrochimica Acta, 2013, 88, pp.6-14. 10.1016/j.electacta.2012.10.002 . hal-01165531

\section{HAL Id: hal-01165531 \\ https://hal.science/hal-01165531}

Submitted on 19 Jun 2015

HAL is a multi-disciplinary open access archive for the deposit and dissemination of scientific research documents, whether they are published or not. The documents may come from teaching and research institutions in France or abroad, or from public or private research centers.
L'archive ouverte pluridisciplinaire HAL, est destinée au dépôt et à la diffusion de documents scientifiques de niveau recherche, publiés ou non, émanant des établissements d'enseignement et de recherche français ou étrangers, des laboratoires publics ou privés. 


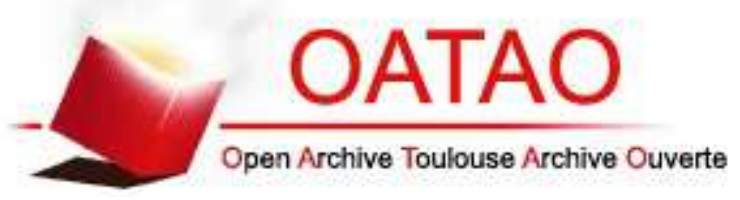

\section{Open Archive TOULOUSE Archive Ouverte (OATAO)}

OATAO is an open access repository that collects the work of Toulouse researchers and makes it freely available over the web where possible.

This is an author-deposited version published in : http://oatao.univ-toulouse.fr/ Eprints ID : 14080

To link to this article : doi: $10.1016 / j$.electacta.2012.10.002

URL : http://dx.doi.org/10.1016/j.electacta.2012.10.002

To cite this version : Mouanga, Maixent and Puiggali, Monique and Tribollet, Bernard and Vivier, Vincent and Pébère, Nadine and Devos, Olivier Galvanic corrosion between zinc and carbon steel investigated by local electrochemical impedance spectroscopy. (2013)

Electrochimica Acta, vol. 88. pp. 6-14. ISSN 0013-4686

Any correspondance concerning this service should be sent to the repository administrator: staff-oatao@ listes-diff.inp-toulouse.fr 


\title{
Galvanic corrosion between zinc and carbon steel investigated by local electrochemical impedance spectroscopy
}

\author{
M. Mouanga ${ }^{a}$, M. Puiggali ${ }^{a}$, B. Tribollet $^{b}$, V. Vivier $^{\mathrm{b}}$, N. Pébère $^{\mathrm{c}}$, O. Devos $^{\mathrm{a}, *}$ \\ a Université de Bordeaux 1, I2M, UMR CNRS 5295, 351 cours de la libération, 33405 Talence Cedex, France \\ ${ }^{\mathrm{b}}$ Université Pierre et Marie Curie, LISE, UPR 15 du CNRS, 75252 Paris Cedex 05, France \\ ' Université de Toulouse, CIRIMAT, UPS/INPT/CNRS, ENSIACET, 4, allée Emile Monso, BP 44362, 31030 Toulouse Cedex 4, France
}

Keywords:

LEIS

Galvanic corrosion

Zinc/steel interface

Radial current

\begin{abstract}
A B S T R A C T
The study of galvanic coupling between two metals is still a relevant topic, particularly in aerospace and automotive industries. The development of local electrochemical techniques leads to a better understanding of the phenomena occurring at the interfacial zone. Galvanic coupling between carbon steel and zinc was investigated by local electrochemical impedance spectroscopy (LEIS) in a $0.06 \mathrm{~g} \mathrm{~L}^{-1} \mathrm{NaCl}$ solution. Voltammetry and conventional electrochemical impedance experiments were also performed to better analyze the local impedance data. Local measurements carried out at a fixed frequency showed that zinc dissolution was more significant at the steel/zinc interface. A particular shape of the local impedance diagram was observed above the zinc surface with the presence of a large inductive loop in the low-frequency range. Numerical simulations, performed by using finite element method, allowed the local experimental diagrams obtained over the zinc sample to be validated taking into account the radial contribution of the current between both materials in galvanic coupling.
\end{abstract}

\section{Introduction}

Zinc is widely used for corrosion protection of steel due to its sacrificial aim: its redox potential being more negative than that of steel under the same conditions, zinc deposits behave as sacrificial anodes and thus offer a cathodic protection to the steel substrate [1-5]. Galvanic corrosion between zinc and steel has been the subject of numerous investigations. Global electrochemical methods, e.g. voltammetry and electrochemical impedance spectroscopy have been often used to investigate this galvanic couple [6-12]. More recently, with the development of local electrochemical techniques, which allow local processes at a microscale to be investigated, the study of galvanic coupling, has known a renewed interest. For example, scanning vibrating electrode technique (SVET) and scanning electrochemical microscopy (SECM) have been used to study the galvanic coupling between zinc and steel (or iron) [13-21]. Simoes et al. reported that the SVET and the SECM techniques provide complementary and consistent information on the local ionic fluxes and local reagents and products concentrations due to the cathodic and anodic reactions occurring above the zinc/iron surface during the galvanic coupling. Furthermore, with the SECM, the concentrations in the aqueous phase can

\footnotetext{
* Corresponding author. Tel.: +33 5400062 19; fax: +33 540006964 .

E-mail address: olivier.devos@u-bordeaux1.fr (O. Devos).
}

be estimated, thus providing in situ information as a function of immersion time [14]. Thebault et al. used SVET to investigate the protective mechanisms occurring on zinc coated steel cut-edges in immersion conditions [15-17]. They reported that the current density measurements over the cut edge of galvanized steel had revealed three distinct kinetic regions: an anode localized over the zinc surface, a region of partial inhibition of the oxygen reduction and the cathodic area on the opposite side of the steel. A model of galvanic corrosion occurring on a galvanized steel cut-edge couple in near neutral conditions was proposed. In the model, the galvanic coupling was supposed to occur in a uniform conductive medium, with oxygen as the only diffusing species [15-17]. Souto et al. showed that SECM greatly enhances the information gathered on corrosion reactions by allowing the spatial distribution of $\mathrm{pH}$ to be imaged (quasi) simultaneously [18]. They also reported that SECM can be employed to detect both the release of zinc(II) ions and the consumption of dissolved oxygen that occurs in the galvanic corrosion of a zinc-iron pair in aqueous solutions without interference from hydrogen evolution [19]. Nevertheless, no studies have been reported on galvanic coupling between zinc and steel by using local electrochemical impedance spectroscopy (LEIS). In recent papers, it was shown that the LEIS technique was well suited for the understanding of corrosion mechanisms in aluminium alloys involving galvanic coupling [22-24].

The present study aims at investigating the galvanic corrosion between zinc and steel by LEIS. The local measurements 


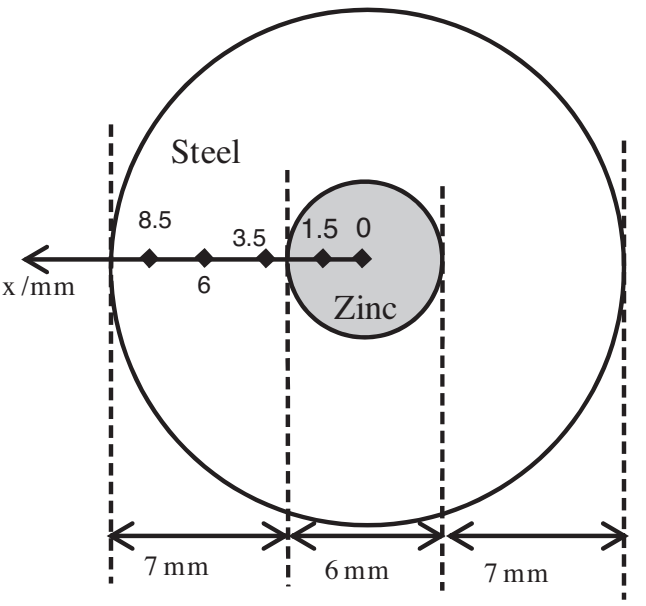

Fig. 1. Schematic representation of the zinc/steel couple.

were analyzed by comparison with experimental results performed with global electrochemical methods. A detailed analysis based on numerical simulation was also developed.

\section{Experimental}

To investigate the coupling effects, the working electrode consisted of a zinc rod (99.9\% of purity provided by Alfa Aesar) of $6 \mathrm{~mm}$ in diameter inserted in the centre of a low carbon steel rod of $20 \mathrm{~mm}$ in diameter (Fig. 1). The chemical composition range (\%wt.) of low carbon steel is $\mathrm{C}(0.30-0.37), \mathrm{Si}(0.15-0.40), \mathrm{Mo}(0.15-0.30)$, $\mathrm{Cr}(0.90-1.20), \mathrm{Mn}(0.60-0.90)$, and $\mathrm{Fe}$ (balance). The electrode was then embedded in an epoxy resin. The same geometry was previously used in the seminal work of Isaacs et al. [25] and for the study of galvanic couplings between aluminium/magnesium [23] and copper/aluminium systems [24]. Experiments were also carried out on a pure zinc rod of $6 \mathrm{~mm}$ in diameter $\left(S=0.28 \mathrm{~cm}^{2}\right)$, and on a carbon steel rod of $20 \mathrm{~mm}$ in diameter $\left(3.14 \mathrm{~cm}^{2}\right)$. To study the galvanic coupling and to compare the measurements on each material, the current and the impedance values must take into account the contribution of the respective surface of zinc and steel in the galvanic couple. Thus, the electrochemical measurements (current and global impedance) on the steel electrode were corrected according to the surface area of the steel in the zinc/steel electrode. Prior to each experiment, the working electrode was mechanically polished with SiC papers up to 4000 grade and then cleaned with distilled water and dried with warm air. All experiments were carried out in a quiescent $0.06 \mathrm{~g} \mathrm{~L}^{-1} \mathrm{NaCl}$ electrolyte (conductivity of about $10^{-4} \mathrm{~S} \mathrm{~cm}^{-1}$ ) as in Refs. [26,27]. This concentration was chosen to perform LEIS with accuracy. Indeed, local measurements required low conductivity to optimize resolution [27].

A three-electrode cell was used for voltammetry and global electrochemical impedance spectroscopy studies. A large platinum grid was used as counter electrode with a saturated calomel electrode (SCE) as reference electrode. The potentiostat was a VersaStat 4 (Princeton Applied Research) controlled by VersaStudio software. Impedance measurements were performed at the corrosion potential in the $10 \mathrm{kHz}$ to $0.01 \mathrm{~Hz}$ frequency range with 10 points per decade and a sine wave perturbation of $20 \mathrm{mV}$ (rms). The current-potential curves were plotted point by point every $50 \mathrm{mV}$ and the current was measured after stabilization to ensure a quasi steady-state condition. The anodic and cathodic curves were obtained separately, starting from the corrosion potential and varying the potential to the anodic or cathodic directions, respectively.

For the local electrochemical impedance measurements, a fiveelectrode configuration was used. A titanium circular grid was used as a counter electrode and saturated calomel electrode (SCE) as a reference electrode. The geometry of the cell was optimized so as to minimize the influence of current and potential distributions [22-24].

LEIS measurements were performed with a PAR Model 370 Scanning Electrochemical Workstation that consisted of a 370 scanning control unit, a Solartron 1287 potentiostat, a Solartron 1250 frequency response analyzer, a high impedance input amplifier using a differential electrometer, and a probe scanning assembly driven in the $x, y$, and $z$ directions. For LEIS measurements, the applied potential amplitude was $20 \mathrm{mV}$ (rms) and the frequencies ranged from $1 \mathrm{kHz}$ to $0.1 \mathrm{~Hz}$ with 10 points per decade.

The local ac-current density, $i_{\text {local }}$, resulted from the local acpotential measurement between the two platinum probes and was calculated using Ohm's law $[25,28]$ :

$i_{\text {local }}=\Delta \varphi \frac{\kappa}{d}$

where $\Delta \varphi$ is the ac-potential difference between the two probes, $\kappa$ is the electrolyte conductivity, and $d$ is the distance between the two probes positioned on and in a conical plastic holder; one is a platinum wire which protrudes from the bottom of the cone and the other is a platinum ring placed around the cone at a distance of $3 \mathrm{~mm}$ from the bottom.

The local impedance $Z_{\text {local }}$ is calculated by the relationship [25,28]:

$Z_{\text {local }}=\frac{\Delta V_{\text {applied }}}{i_{\text {local }}}$

where $\Delta V_{\text {applied }}$ is the ac-potential difference between the working electrode surface and the reference electrode in the bulk solution.

Fundamental of LEIS measurements are detailed in Refs. $[22,25,28-30]$. This technique is based on the pioneering work of Isaac's group $[25,28]$ and takes into account the recent developments to improve the measurements and interpretation of experimental results $[22,29,30]$.

Numerical calculations were performed to provide a fine description of the potential and current distributions on the disk electrode surface and in the surrounding electrolyte allowing the simulation of LEIS diagrams. Calculations were achieved using a finite element package Comsol Multiphysics ${ }^{\odot}$ with the conductive dc module in a 2D axial symmetry. The mesh size was refined to obtain a numerical error lower than $0.1 \%$ evaluated from the net current of the system which is the sum of the current passing through both electrodes. The boundary conditions for the numerical calculations were determined from the analysis of experimental measurements performed on individual zinc and steel electrodes.

\section{Results and discussion}

\subsection{Voltammetry}

The open circuit potential (OCP) of zinc, steel and zinc/steel galvanic couple was measured in the $0.06 \mathrm{~g} \mathrm{~L}^{-1} \mathrm{NaCl}$ solution (Fig. 2). After $1 \mathrm{~h}$ of immersion, the OCP values were $-1.01,-0.49$, and $-0.80 \mathrm{~V} / \mathrm{SCE}$ for the zinc, the steel, and the zinc/steel couple, respectively. The large difference in potential between the two metals (about $0.6 \mathrm{~V}$ ) clearly indicates the possibility of a galvanic coupling, and the OCP value of zinc/steel galvanic couple, which is positioned between zinc and steel, is consistent with such an assumption. Fig. 3 shows the current-potential curves for the zinc, the steel and the zinc/steel couple. As expected, the curve corresponding to the galvanic couple is between the two others on the whole investigated potential range. At the corrosion potential of the zinc/steel galvanic couple, the net current is the algebraic sum of the anodic current (zinc oxidation) and the cathodic current (oxygen reduction on the 


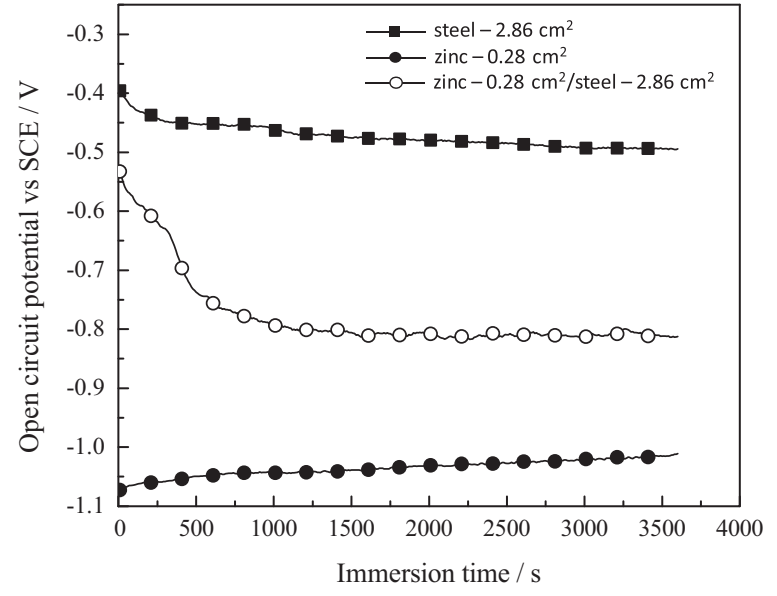

Fig. 2. Open circuit potential as a function of time in the $0.06 \mathrm{~g} \mathrm{~L}^{-1} \mathrm{NaCl}$ solution: carbon steel, zinc and zinc/steel couple.

steel surface). It is noteworthy that the corrosion potential of the galvanic couple was controlled by the cathodic reaction of dissolved oxygen (plateau current). Note that the SVET has been already used to determine localized polarization curves demonstrating the diffusion limited reaction on the steel and electron transfer limited reaction on zinc as demonstrated here in galvanic coupling [20].

\subsection{Global EIS}

Fig. 4 shows the global impedance diagrams (Nyquist plots) obtained for the steel and the zinc samples polarized at $-0.8 \mathrm{~V} / \mathrm{SCE}$ (i.e. at a potential corresponding to the OCP of the zinc/steel couple). The diagram for the galvanic couple is also presented. For the steel sample, a capacitive behaviour was observed in the studied frequency range, which is in agreement with the fact that at $-0.8 \mathrm{~V} / \mathrm{SCE}$, the measurement was performed on the cathodic plateau ascribed to the oxygen reduction (Fig. 3).

The impedance diagram for the zinc sample at $-0.8 \mathrm{~V} / \mathrm{SCE}$ shows a capacitive loop with lower amplitude, followed at low frequencies by an inductive response identifying several relaxation time constants. However, the inductive part was not very well defined. At $-0.8 \mathrm{~V} / \mathrm{SCE}$, zinc is anodically polarized. The shift of the modulus in low frequencies was probably due to a small increase of the stationary current versus time during zinc dissolution. The shape of

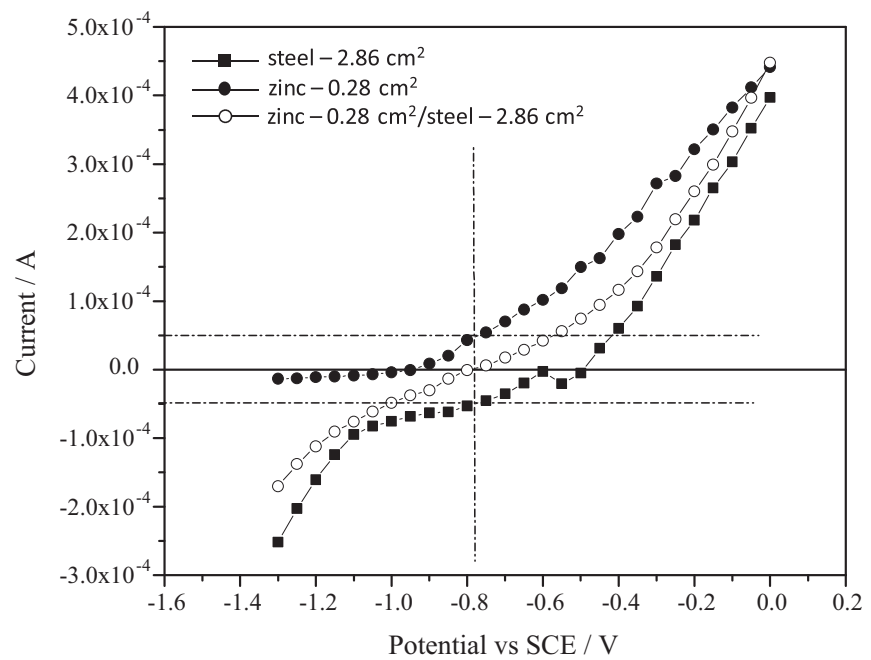

Fig. 3. Current-potential curves obtained for the different systems after $1 \mathrm{~h}$ of immersion in the $0.06 \mathrm{~g} \mathrm{~L}^{-1} \mathrm{NaCl}$ solution: carbon steel, zinc and zinc/steel couple.

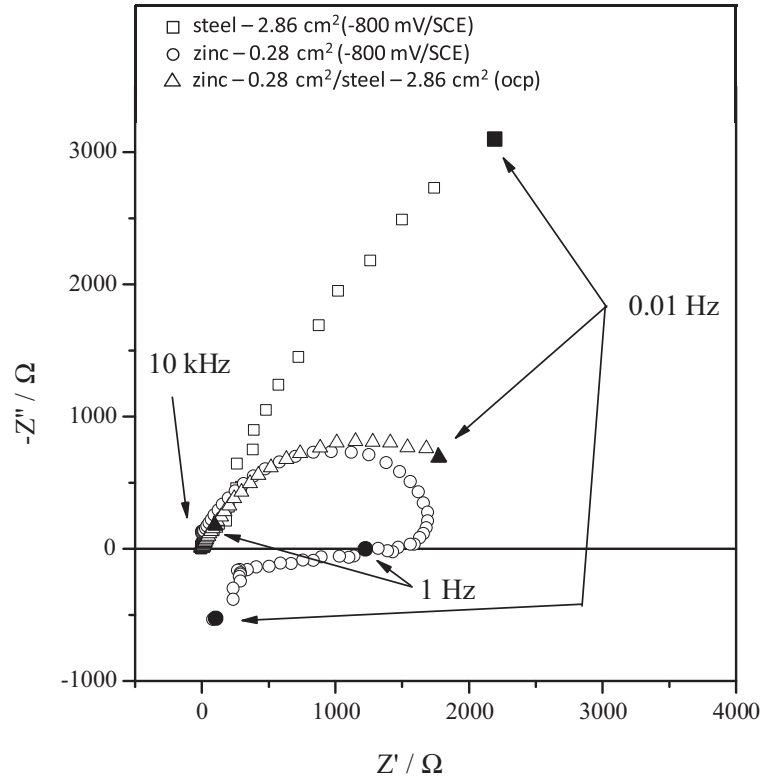

Fig. 4. Global impedance diagrams obtained at $-0.8 \mathrm{~V} / \mathrm{SCE}$ in the $0.06 \mathrm{~g} \mathrm{~L}^{-1} \mathrm{NaCl}$ solution for the steel sample, the zinc sample and the zinc/steel couple.

the diagram is in agreement with previous results obtained on zinc dissolution where adsorbed species were involved in the corrosion process [31-34]. The diagram of the zinc/steel couple at the corrosion potential presented a capacitive response. The size of the loop was in between the impedance of the two metals (steel and zinc) studied separately.

\subsection{Local EIS}

Prior to measure the LEIS diagrams on different locations on the zinc/steel surface, a line scan at a fixed frequency $(1 \mathrm{~Hz})$ was performed (Fig. 5). The bi-electrode was moved by step of $240 \mu \mathrm{m}$ along the diameter of the galvanic couple to visualize the two metals and the interface. High admittance modulus was measured above the zinc/steel interfacial zone. This result indicates the existence of higher current density due to a stronger activity of zinc dissolution at the zinc/steel interface. Similar results were observed with the $\mathrm{Al} / \mathrm{Mg}$ couple [23] and the $\mathrm{Al} / \mathrm{Cu}$ couple [24]. A high dissolution rate of zinc at the interface must be accompanied by an

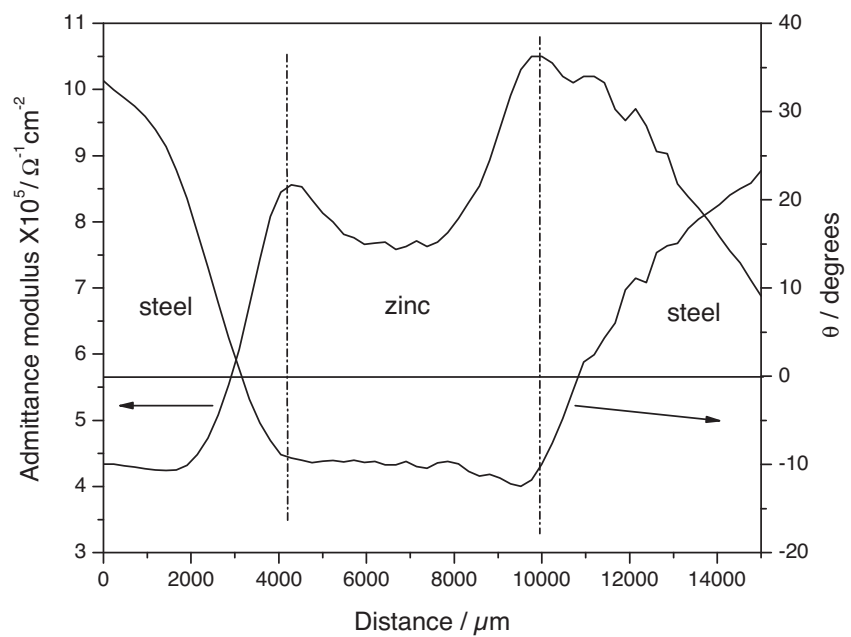

Fig. 5. Line scan at $1 \mathrm{~Hz}$ above the zinc/steel couple in the $0.06 \mathrm{~g} \mathrm{~L}^{-1} \mathrm{NaCl}$ solution: admittance modulus and phase. 
(a)

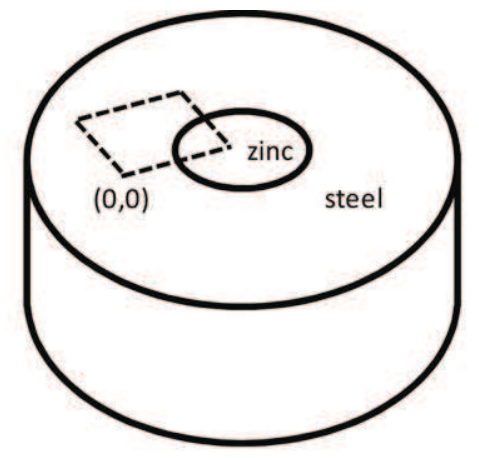

(b)

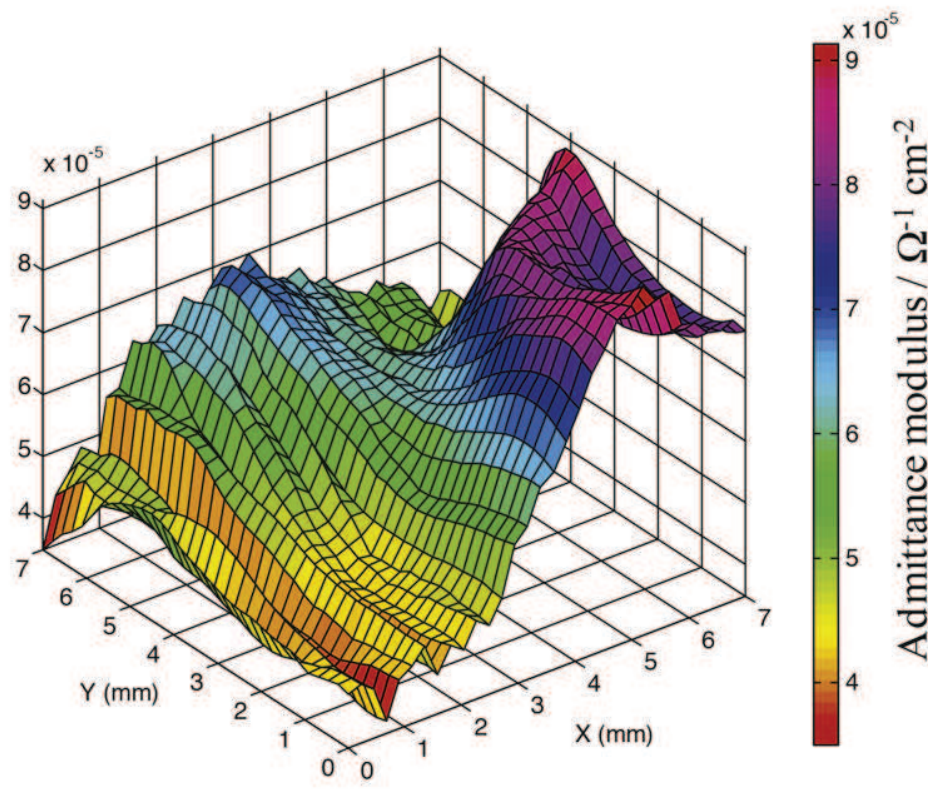

(c)

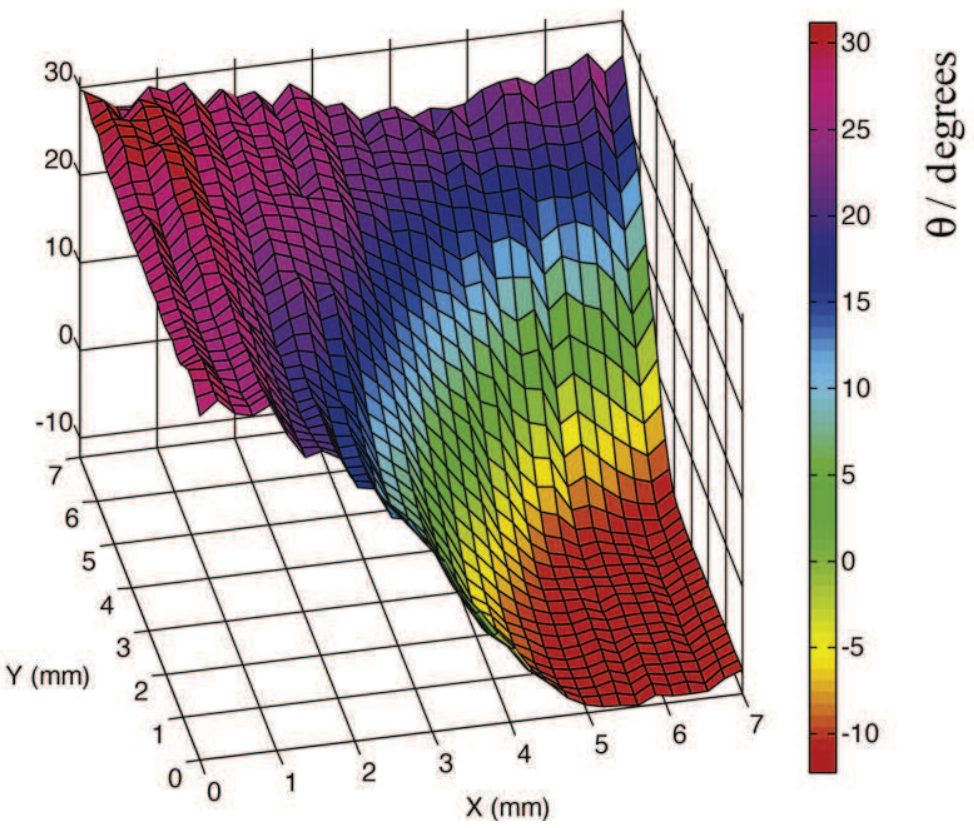

Fig. 6. Mappings at $1 \mathrm{~Hz}$ above the zinc/steel couple in the $0.06 \mathrm{~g} \mathrm{~L}^{-1} \mathrm{NaCl}$ solution: (a) scanned area, (b) admittance modulus and (c) phase. 
increase of the oxygen reduction on the carbon steel close to the interface, leading to local variations of the chemical composition of the electrolyte from the beginning of immersion. It results in a local pH increase of the electrolyte at the zinc/steel interface. It can also be observed that at $1 \mathrm{~Hz}$, the phase of the impedance is positive over the steel and gradually changes to a negative value when the probe was moved above the zinc surface.

A LEIS mapping over the zinc/steel galvanic couple was also performed. The scanned surface area was a square of $7 \mathrm{~mm} \times 7 \mathrm{~mm}$ (Fig. 6a). Fig. 6b and c shows the mapping in Bode coordinates (admittance modulus in Fig. 6b and phase angle in Fig. 6c) carried out at $1 \mathrm{~Hz}$ in $0.06 \mathrm{~g} \mathrm{~L}^{-1} \mathrm{NaCl}$ solution. These maps confirm the results obtained in Fig. 5 (line scan) over a larger area of the galvanic couple, near the interface between both materials. Again, the highest admittance modulus was measured at the vicinity of the zinc/steel interfacial zone and the positive impedance phase was measured over the steel and changed to a negative value when the probe was located above the zinc. The phase angle measurements were consistent with those obtained by global EIS (Fig. 4). Indeed, the phase measured at $1 \mathrm{~Hz}$ on steel at $-0.8 \mathrm{~V} / \mathrm{SCE}$ corresponded to a capacitive response (positive phase) whereas the phase measured on zinc in the same conditions characterized an inductive process (negative phase). Note that Fig. 6b exhibits an increase of the admittance far from the zinc in coordinates ( $x=3 \mathrm{~mm}$ and $y=7 \mathrm{~mm}$ ). This artefact is not consistent with Fig. 5. Some authors mentioned the presence of precipitated zinc corrosion products on the steel in more concentrated $\mathrm{NaCl}$ solution using a similar bi-electrode [20]. The change of the local current distribution occurring by the presence of such products should explain the unexpected increase of admittance in Fig. 6b. Nevertheless, the very low $\mathrm{NaCl}$ concentration and the fact that the experiments were conducted after $1 \mathrm{~h}$ of filling up the five-electrode cell did not lead to observe any precipitate on the electrode surface.

Then, LEIS measurements were performed above both metals in a coupling situation with the radial position of the bi-electrode as a parameter. The LEIS diagrams are shown in Fig. 7 in Nyquist coordinates. Over the steel, a high-frequency inductive feature was observed with weak amplitude by comparison with the capacitive low-frequency contribution (Fig. 7a). The inductive response can be attributed to the local ohmic impedance explained by the frequency dispersion associated with the geometry of disk electrodes and by the current and potential distributions at and around the interface formed by the two metals [30]. The capacitive loop can be attributed to the charge transfer process of the oxygen reduction on the steel surface. The amplitude of the loop significantly decreased as the LEIS probe was closer to the zinc/steel interface in accordance with the increase of the local current at the vicinity of the zinc/steel interface as observed in Figs. 5 and 6. When the probe is located on the zinc surface, the shape of the LEIS diagrams drastically changed (Fig. 7b). The LEIS diagrams present, in the high-frequency range, a small capacitive loop followed by a large inductive loop. The LEIS responses observed on the zinc surface in galvanic coupling conditions are surprising. Indeed, the impedance corresponding to the charge transfer of zinc dissolution (capacitive behaviour) was almost negligible in comparison with the inductive response. This result agreed with the line scan in Fig. 5 . Indeed, at $1 \mathrm{~Hz}$, the phase was positive over the steel (capacitive loop) while it was negative over the zinc (inductive loop). Thus, the capacitive loop observed on the local impedance diagram over the steel in the zinc/steel couple was attributed to the reduction process of dissolved oxygen while the inductive loop, in the local diagram observed above the zinc surface, characterized the adsorption process in the mechanism of zinc dissolution. Meanwhile, the LEIS diagrams obtained over the zinc in the zinc/steel couple led to unexpected results (Fig. 7) showing that the amplitude of the capacitive loop was much smaller than that of the inductive response. To better understand
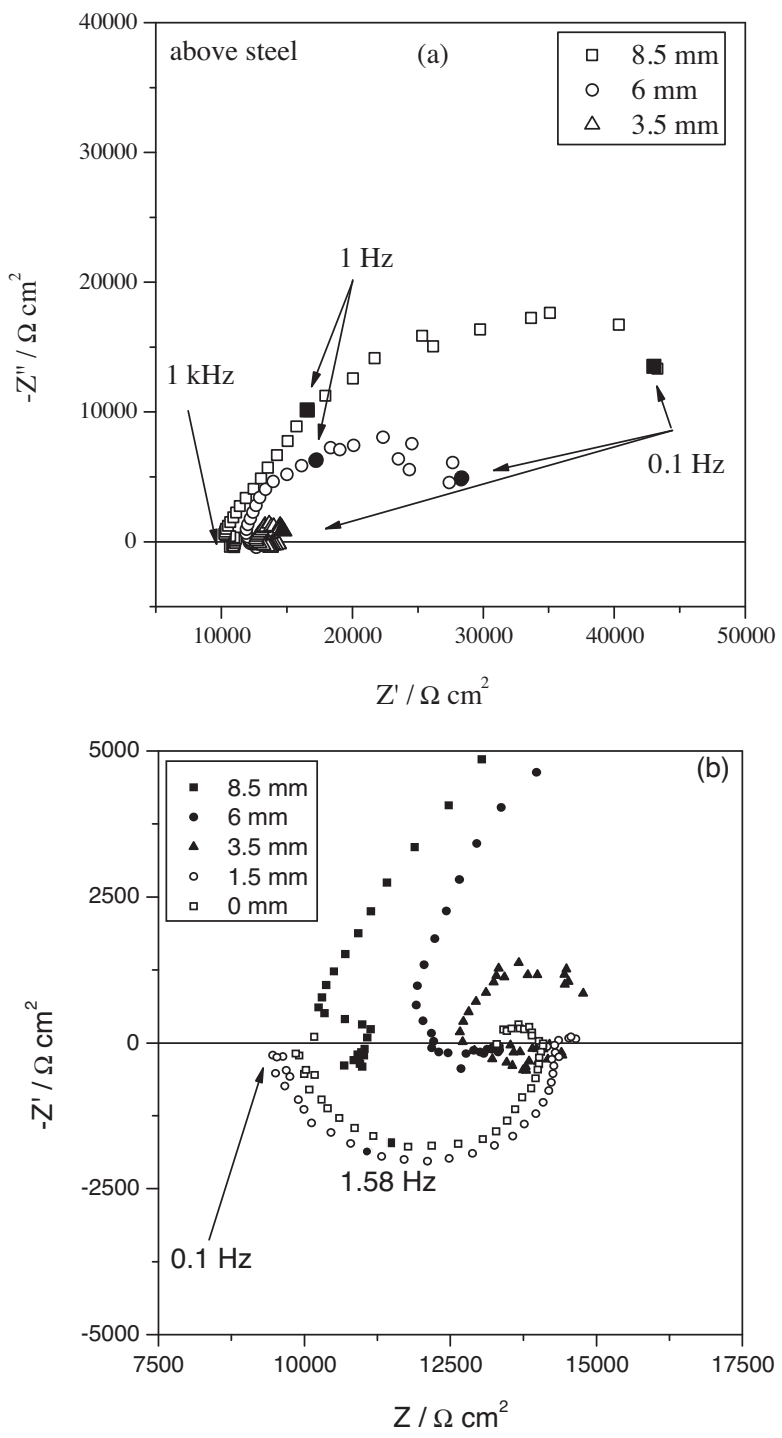

Fig. 7. Local impedance diagrams obtained above the zinc/steel couple: (a) frequency range from $1 \mathrm{kHz}$ to $0.1 \mathrm{~Hz}$ and (b) an expanded view of LEIS diagrams over the zinc; $[\mathrm{NaCl}]=0.06 \mathrm{~g} \mathrm{~L}^{-1}$.

such phenomenon both local and global impedance measurements were performed on the zinc sample without galvanic coupling and at different potentials.

\subsection{Comparison between EIS and LEIS of pure zinc}

Fig. 8 shows global and local impedance diagrams in Nyquist coordinates obtained on the zinc surface in the $\mathrm{NaCl} 0.06 \mathrm{~g} \mathrm{~L}^{-1}$ solution. Fig. 9 shows the same results in Bode coordinates. The chosen potentials were the open circuit potential of zinc $(-1 \mathrm{~V} / \mathrm{SCE})$, the open circuit potential of the zinc/steel couple $(-0.8 \mathrm{~V} / \mathrm{SCE})$ and a more anodic potential $(-0.7 \mathrm{~V} / \mathrm{SCE})$. With both techniques, the diagrams were close for the three investigated potentials. The global and local diagrams exhibited a high-frequency capacitive loop attributed to the charge transfer of the zinc dissolution. As expected, the size of the capacitive loop decreased when the anodic potential increased (the charge transfer resistance is inversely proportional to the faradaic current). A shift of the time constant in high frequencies was also observed (Fig. 9). The shift of the time constant as the anodic potential increases was observed by Wu et al. in the case of iron in $0.5 \mathrm{M} \mathrm{H}_{2} \mathrm{SO}_{4}$ solution due to the adsorption 

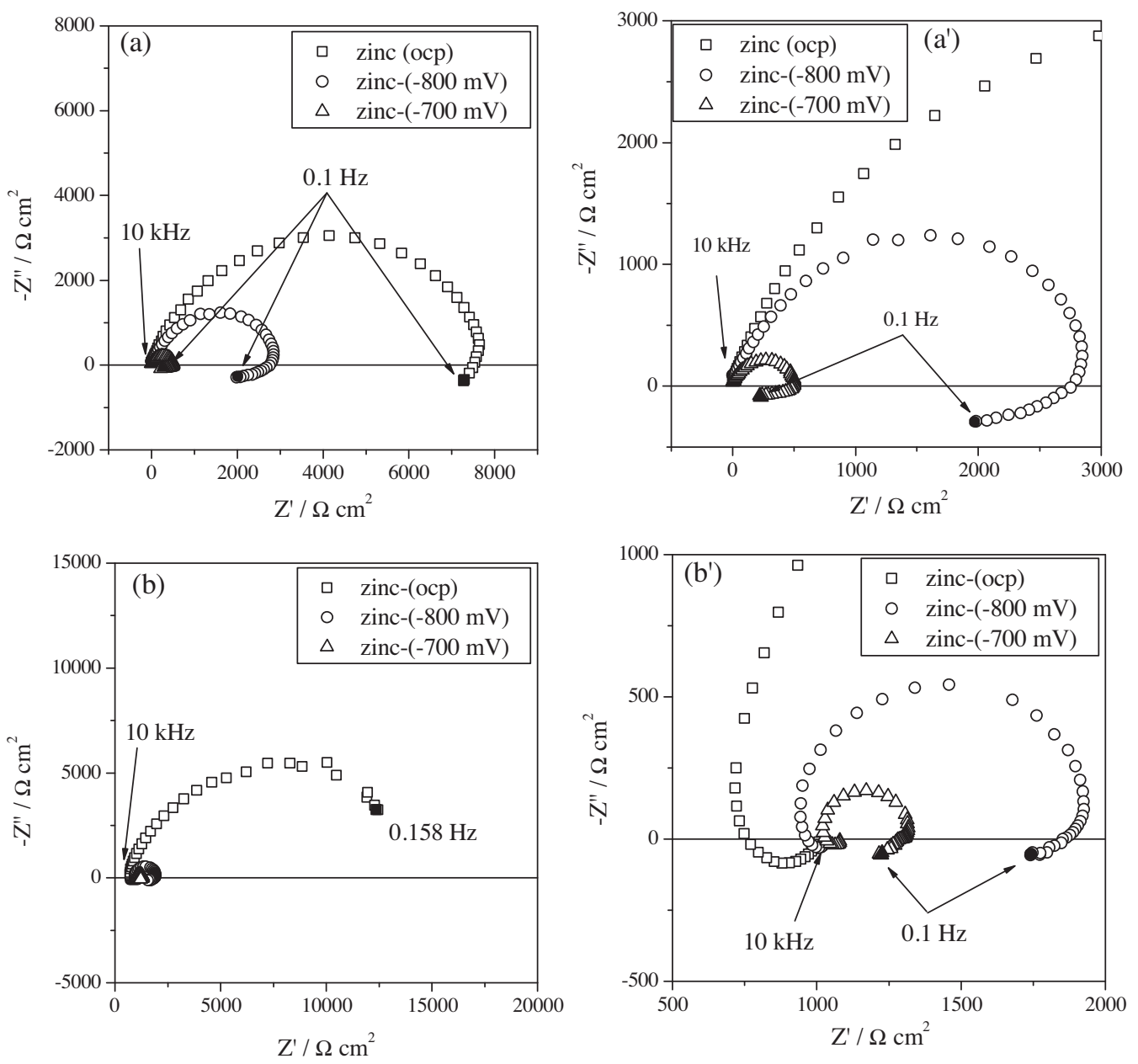

Fig. 8. (a) Global and (b) local electrochemical impedance diagrams in Nyquist coordinates obtained on the zinc surface for different potential values in the $0.06 \mathrm{~g} \mathrm{~L}^{-1} \mathrm{NaCl}$ solution. ( $a^{\prime}$ and $b^{\prime}$ ) Global and local expanded views respectively.

of intermediate species [35]. Simulation methods also showed a shift in frequencies by polarizing the working electrode [36]. As in Ref. [35], in the present study, the shift of the time constant as the anodic potential increases is attributed to an increase in the rate of zinc dissolution. Note that the frequency range of the capacitive loop at different potentials was similar using the global and local impedances. The presence of adsorption processes in the low-frequency range was observed both on the global and on the local spectra (Figs. 8 and 9). Bode diagrams (Fig. 9) shows that the frequency identifying the transition between the capacitive and inductive responses was roughly the same using EIS and LEIS. A shift of this characteristic frequency was observed when the potential varied anodically. Thus, the global and local diagrams are relatively similar when the zinc was not in galvanic contact with the steel. This result validated the local impedance measurements but did not explain the shape of the local diagrams obtained on the zinc sample in coupling situation (Fig. 7). The local impedance diagram of zinc polarized at $-0.8 \mathrm{~V} / \mathrm{SCE}$, which is the OCP of zinc/steel couple, was drastically different from the local diagram obtained over the zinc in galvanic couple.

\subsection{Modelling of the coupling}

To account for the experimental results obtained for the zinc/steel couple, numerical simulations were performed using finite element method.
When the electrode is immersed in the electrolyte, the potential $\Phi$ in the solution surrounding the electrode is governed by the Laplace equation, which is expressed in cylindrical coordinates $(r, \theta, z)$ as:

$\frac{1}{r} \frac{\partial}{\partial r}\left(r \frac{\partial \Phi}{\partial r}\right)+\frac{1}{r^{2}} \frac{\partial^{2} \Phi}{\partial \theta^{2}}+\frac{\partial^{2} \Phi}{\partial z^{2}}=0$

where $z$ is the normal distance to the electrode surface, $r$ is the radial coordinate, and $\theta$ is the azimuth.

Under the assumption of a kinetic regime, the current density at the electrode surface can be expressed as:

$I=-\left.\kappa \frac{\partial \Phi}{\partial z}\right|_{z=0}$

where $\kappa$ is the electrolyte conductivity.

As previously mentioned, on the steel electrode, the cathodic reaction is the oxygen reduction reaction. However, as shown in Fig. 3, this reaction is diffusion limited and its kinetics was thus disregarded.

In chloride containing solution, the zinc dissolution mechanism can be expressed according to the following reaction pathway, as already described by Cachet et al. [33,34]. The first step corresponds to the formation of a monovalent intermediate $\mathrm{Zn}_{\mathrm{ads}}^{\mathrm{I}}$

$\mathrm{Zn} \underset{k_{-1}}{\stackrel{k_{1}}{\rightleftarrows}} \mathrm{Zn}_{\mathrm{ads}}^{\mathrm{I}}\left(\theta_{1}\right)+e^{-}$ 

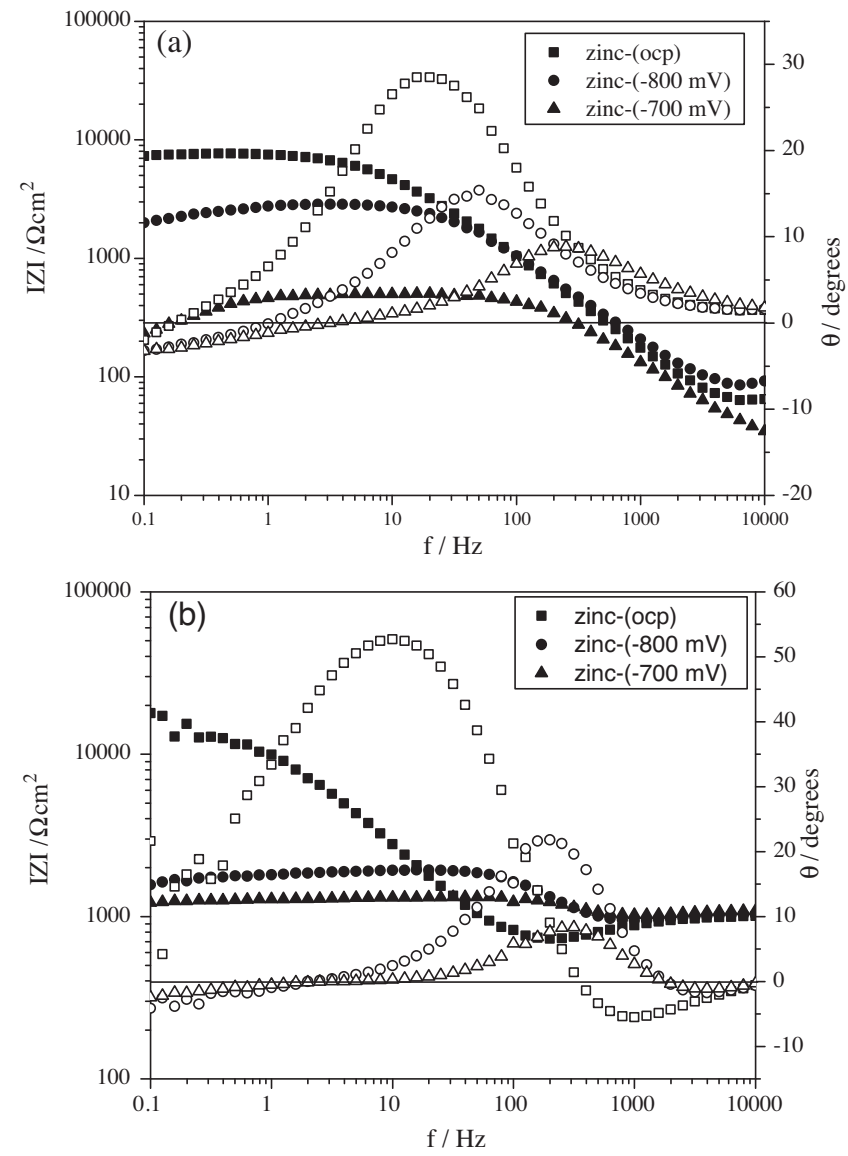

Fig. 9. (a) Global and (b) local electrochemical impedance diagrams in Bode coordinate obtained on the zinc surface for different potential values in the $0.06 \mathrm{~g} \mathrm{~L}^{-1} \mathrm{NaCl}$ solution (full symbols for impedance modulus and open symbols for phase angle). The horizontal line indicates $0^{\circ}$ in the phase axis.

where $\theta$ is the covered fraction by the adsorbed species with $0<\theta<1$.

The monovalent intermediate can dissolve:

$\mathrm{Zn}_{\mathrm{ads}}^{\mathrm{I}}\left(\theta_{1}\right) \stackrel{k_{2}}{\longrightarrow} \mathrm{Zn}_{\mathrm{ads}}^{\mathrm{II}}\left(\theta_{1}\right)+e^{-}$

$\mathrm{Zn}_{\mathrm{ads}}^{\mathrm{II}}\left(\theta_{2}\right) \stackrel{k_{3}}{\longrightarrow} \mathrm{Zn}_{\text {sol }}^{\mathrm{II}}$

The last dissolution reaction to be considered is the slow formation of hydroxide whose removal is anodically activated:

$\mathrm{ZnOH}_{\mathrm{ads}}\left(\theta_{3}\right) \underset{k_{-4}}{\stackrel{k_{4}}{\rightleftarrows}} \mathrm{ZnOH}_{\mathrm{sol}}^{+}+e^{-}$

The monovalent intermediate can also act as a catalyst:

$\mathrm{Zn}+\mathrm{Zn}_{\mathrm{ads}}^{\mathrm{I}}\left(\theta_{1}\right) \stackrel{k_{5}}{\longrightarrow} \mathrm{Zn}_{\mathrm{sol}}^{\mathrm{II}}+2 \mathrm{e}^{-}+\mathrm{Zn}_{\mathrm{ads}}^{\mathrm{I}}\left(\theta_{1}\right)$

The cathodic reaction on the zinc surface is the reduction of the oxygen which is assumed to occur on the partial electrode surface $1-\theta_{1}-\theta_{2}$

$\mathrm{O}_{2}+2 \mathrm{H}_{2} \mathrm{O}+4 \mathrm{e}^{-} \stackrel{k_{6}}{\longrightarrow} 4 \mathrm{OH}^{-}$

The rate constant of electrochemical reaction are assumed to follow a Tafel's law:

$K_{1}=K_{1}(0) e^{b_{1} \Phi}$ and $K_{-1}=K_{-1}(0) e^{-b_{1} \Phi}$

$K_{2}=K_{2}(0) e^{b_{2} \Phi}$

$K_{4}=K_{4}(0) e^{b_{4} \Phi}$
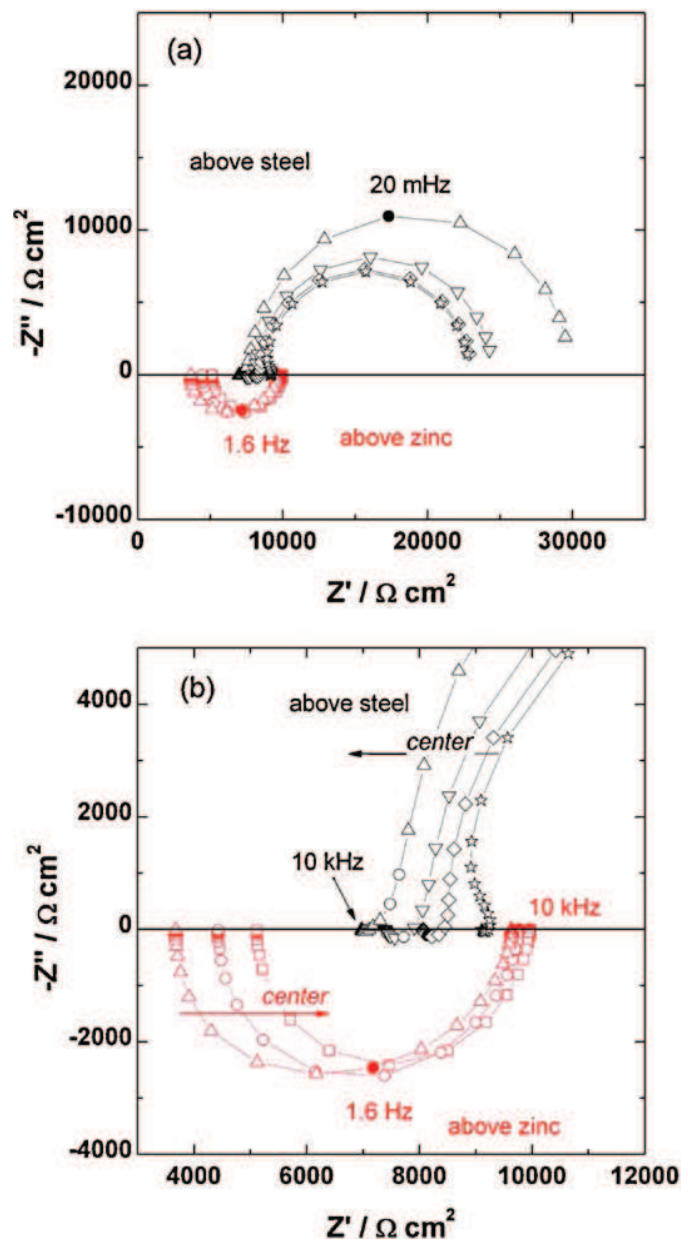

Fig. 10. (a) Calculated local impedance diagrams with radial position as a parameter for the galvanic coupling between zinc and steel, (b) zoom of the high frequency range.

As stated by Cachet et al. [30], the formation of $\mathrm{ZnOH}_{\text {ads }}$ might express the chemical oxidation of zinc by the electrolytic solution and, for simplicity, its rate constant $k_{-4}$ was considered as potential-independent.

$K_{5}=K_{5}(0) e^{b_{5} \Phi}$

$K_{6}=K_{6}(0) e^{b_{6} \Phi}$

with $K_{n}(0)$ is the electrochemical kinetic constant of the reaction $(n)$ at the corrosion potential:

$b_{n}=\alpha_{n} \frac{z_{n} F}{R T}$

$\alpha_{n}$ is the charge transfer coefficient of the reaction $(n), z$ the number of electrons, $F$ the Faraday constant, $R$ the gas constant and $T$ the temperature.

The detailed analysis of this system can be found in Refs [33,34]. In the present work, the linearized formulation of the impedance was used as boundary condition for describing zinc dissolution. Such an approach allows describing the galvanic process taking into account both the kinetics of individual electrode reaction and the current and potential distributions.

Thus, the calculated local impedance diagrams (Fig. 10) provided qualitative good agreement with the experimental diagrams. Over the steel, a high-frequency inductive feature was observed with weak amplitude by comparison with the capacitive low-frequency contribution as observed experimentally. It was noticed in Fig. 10b that the high-frequency inductive loop depended of the radial 
position where the radial position is indicated by the arrows. The same experimental phenomenon was experimentally measured in Fig. 7. In accordance with the experimental diagrams, the amplitude of the low-frequency loop decreased as the LEIS probe was closer to the zinc/steel interface. Note that the calculated data at $20 \mathrm{mHz}$ were not obtained by the experimental measurements because the last frequency on the impedance diagram was $0.1 \mathrm{~Hz}$.

When the probe was located on the zinc surface, the large inductive loop was obtained as in Fig. 7b. Note that the simulated and experimental high-frequency responses were quite independent on the radial position (only a small shift of the real part of the local impedance). Over the zinc, by comparing the experimental and the calculated impedance diagrams, the inductive loops are in good accordance. The amplitude of the loops was close and experimental data at $1.58 \mathrm{~Hz}$ (Fig. 7b) appears at $1.6 \mathrm{~Hz}$ in calculated data (Fig. 10). Moreover, the calculated diagrams confirmed that smaller amplitude of the inductive response is observed when the probe is shifted above the zinc centre by comparison with the diagrams obtained close to the zinc/steel interface. However, the small capacitive loop at high frequencies obtained with the experimental data was not observed. These discrepancies between experiments and numerical calculations over the zinc were attributed to the fact that the system used for performing local impedance measurements could not provide the precise conditions assumed for the calculations. So that, the numerical simulations allowed the experimental impedance diagrams obtained over the zinc to be validated. The simulation allows interpreting the unusual shape of the impedance diagrams obtained on zinc by LEIS in galvanic coupling with steel. It has to be noticed that such impedance features were not reproduced by EIS and LEIS when zinc alone was under corrosion polarization. A weakness of the model is that concentration variations in the vicinity of the interface are neglected.

The highlight of this study conducted by LEIS is the active dissolution of zinc observed at the vicinity of zinc/steel interface due to the galvanic coupling. The other interesting aspect is that the combined effect of the radial component of the current and the inductive phenomenon commonly observed on the global impedance diagrams of zinc leads to an unexpected local impedance diagram consisting of a large inductive loop.

\section{Conclusions}

The local electrochemical behaviour was studied in galvanic corrosion between zinc and steel metals. It was shown that the current distribution was higher at the interface between both materials in accordance with previous works devoted to galvanic coupling between $\mathrm{Al}$ and $\mathrm{Mg}$ or $\mathrm{Al}$ and $\mathrm{Cu}[23,24]$. It leads to a higher corrosion process of zinc in the vicinity of steel. The mechanism of zinc dissolution was studied in order to investigate the LEIS diagrams on zinc in galvanic coupling, and a good agreement was shown between experimental and simulated diagrams. It was particularly shown that local impedance responses were drastically different when the bi-electrode was positioned above zinc alone in corrosion condition and zinc in galvanic coupling with steel even if zinc was polarized at the same potential in both cases. Indeed, a large capacitive loop followed by a smaller inductive loop in low frequencies was observed above zinc alone whereas a capacitive response with small amplitude followed by a larger inductive loop was obtained in galvanic coupling with steel. It means that LEIS diagrams must be analyzed carefully to study the galvanic coupling. Indeed, it was shown that the contribution of the radial component of the current involved between both metals was not negligible in particular in the low frequency range of LEIS.

\section{References}

[1] M. Mouanga, L. Ricq, G. Douglade, J. Douglade, P. Berçot, Influence of coumarin on zinc electrodeposition, Surface and Coatings Technology 201 (2006) 762.

[2] M. Mouanga, L. Ricq, J. Douglade, P. Berçot, Effects of some additives on the corrosion behaviour and preferred orientations of zinc obtained by continuous current deposition, Journal of Applied Electrochemistry 37 (2007) 283.

[3] K.M.S. Youssef, C.C. Koch, P.S. Fedkiw, Improved corrosion behavior of nanocrystalline zinc produced by pulse-current electrodeposition, Corrosion Science 46 (2004) 51.

[4] G. Trejo, H. Ruiz, R.O. Borges, Y. Meas, Influence of polyethxylated additives on zinc electrodeposition from acidic solutions, Journal of Applied Electrochemistry 31 (2001) 685.

[5] X.G. Zhang, Corrosion and Electrochemistry of Zinc, Plenum Press, New York/London, 1996.

[6] X.G. Zhang, Galvanic corrosion of zinc and its alloys, Journal of the Electrochemical Society $143(1996) 1472$

[7] J.H.O.J. Wijjenberg, J.T. Stevels, J.H.W. de Wit, Galvanic coupling of zinc to steel in alkaline solutions, Electrochimica Acta 43 (1997) 649.

[8] A.P. Yadav, A. Nishikata, T. Tsuru, Degradation mechanism of galvanized steel in wet-dry cyclic environment containing chloride ions, Corrosion Science 46 (2004) 361.

[9] R.R. Zahran, G.H. Sedahmed, Galvanic corrosion of zinc in turbulently moving saline water containing drag reducing polymers, Materials Letters 31 (1997) 29.

[10] X.G. Zhang, E.M. Valeriote, Galvanic protection of steel and galvanic corrosion of zinc under thin layer electrolytes, Corrosion Science 34 (1993) 1957.

[11] A. Besseyrias, F. Dalard, J.J. Rameau, H. Baudin, A study of galvanic corrosion during coulometric dissolution of galvannealed steel, Corrosion Science 37 (1995) 587.

[12] X.G. Zhang, Galvanic protection distance of zinc-coated steels under various environmental conditions, Corrosion 56 (2000) 139.

[13] R.M. Souto, Y. Gonzalez-Garcia, A.C. Bastos, A.M. Simoes, Investigating corrosion processes in the micrometric range: A SVET study of the galvanic corrosion of zinc coupled with iron, Corrosion Science 49 (2007) 4568.

[14] A.M. Simoes, A.C. Bastos, M.G. Ferreira, Y. Gonzalez-Garcia, R.M. Souto, Use of SVET and SECM to study the galvanic corrosion of an iron-zinc cell, Corrosion Science 49 (2007) 726.

[15] F. Thebault, B. Vuillemin, R. Oltra, C. Allely, K. Ogle, Protective mechanisms occuring on zinc coated steel cut-edges in immersion conditions, Electrochimica Acta 56 (2011) 8347

[16] F. Thebault, B. Vuillemin, R. Oltra, K. Ogle, C. Allely, Investigations of self-healing mechanism on galvanized steels cut edges by coupling SVET and numerical modeling, Electrochimica Acta 53 (2008) 5226.

[17] F. Thebault, B. Vuillemin, R. Oltra, C. Alley, K. Ogle, Modeling bimetallic corrosion under thin electrolyte films, Corrosion Science 53 (2011) 201.

[18] J. Izquierdo, L. Nagy, A. Varga, J.J. Santana, G. Nagy, R.M. Souto, Spatially resolved measurement of electrochemical activity and $\mathrm{pH}$ distributions in corrosion processes by scanning electrochemical microscopy using antimony microelectrode tips, Electrochimica Acta 56 (2011) 8846.

[19] R.M. Souto, Y.G. Garcia, D. Battistel, S. Daniele, On the use of mercury-coated tips in scanning electrochemical microscopy to investigate galvanic corrosion process involving zinc and iron, Corrosion Science 55 (2012) 401.

[20] K. Ogle, V. Baudu, L. Garrigues, X. Pilippe, Localized electrochemical methods applied to cut edge corrosion, Journal of the Electrochemical Society 147 (2000) 3654.

[21] K. Ogle, S. Morel, D. Jacquet, Observation of self-healing functions on the cut edge of galvanized steel using SVET and $\mathrm{pH}$ microscopy, Journal of the Electrochemical Society 153 (2006) B1.

[22] C. Blanc, M.E. Orazem, N. Pebere, B. Tribollet, V. Vivier, S. Wu, The origin of the complex character of the ohmic impedance, Electrochimica Acta 55 (2010) 6313.

[23] L. Lacroix, C. Blanc, N. Pebere, B. Tribollet, V. Vivier, Localized approach to galvanic coupling in an aluminium-magnesium system, Journal of the Electrochemical Society 158 (2009) C259.

[24] J.B. Jorcin, C. Blanc, N. Pebere, B. Tribollet, V. Vivier, Galvanic coupling between pure copper and pure aluminium: Experimental approach and mathematical model, Journal of the Electrochemical Society 155 (2008) C46.

[25] R.S. Lillard, P.J. Moran, H.S. Isaacs, A novel method for generating quantitative local electrochemical impedance spectroscopy, Journal of the Electrochemical Society 139 (1992) 1007.

[26] J.B. Jorcin, H. Krawiec, N. Pebere, V. Vignal, Comparaison of local electrochemical impedance measurements derived from bi-electrode and microcapillary techniques, Electrochimica Acta 54 (2009) 5775.

[27] T.T.X. Huang, T.A. Truc, T.H. Nam, V.K. Oanh, J.B. Jorcin, N. Pebere, Corrosion protection of carbon steel by an epoxy resin containing organically modified clay, Surface and Coatings Technology 201 (2007) 7408.

[28] F. Zou, D. Thierry, H.S. Isaacs, A high resolution probe for localized electrochemical impedance spectroscopy measurements, Journal of the Electrochemical Society 144 (1997) 1957

[29] I. Frateur, V.M.W. Huang, M.E. Orazem, B. Tribollet, V. Vivier, Experimental issues associated with measurement of local electrochemical impedance, Journal of the Electrochemical Society 154 (2007) C719.

[30] V.M.W. Huang, S.L. Wu, M.E. Orazem, N. Pebere, B. Tribollet, V. Vivier, Local electrochemical impedance spectroscopy: A review and some recent developments, Electrochimica Acta 56 (2011) 8048. 
[31] C. Cachet, F. Ganne, G. Maurin, J. Petitjean, V. Vivier, R. Wiart, EIS investigation of zinc dissolution in aerated sulfate medium. Part I: bulk zinc, Electrochimica Acta 47 (2001) 509.

[32] C. Cachet, F. Ganne, S. Joiret, G. Maurin, J. Petitjean, V. Vivier, R. Wiart, EIS investigation of zinc dissolution in aerated sulphate medium. Part II: zinc coatings, Electrochimica Acta 47 (2002) 3409

[33] C. Cachet, R. Wiart, The kinetics of zinc dissolution in chloride electrolytes: Impedance measurements and electrode morphology, Journal of Electroanalytical Chemistry 111 (1980) 235.
[34] C. Cachet, R. Wiart, Reaction mechanism for zinc dissolution in chloride electrolytes, Journal of Electroanalytical Chemistry 129 (1981) 103.

[35] S.L. Wu, M.E. Orazem, B. Tribollet, V. Vivier, Impedance of a disk electrode with reactions involving an adsorbed intermediate: Experimental and simulation analysis, Journal of the Electrochemical Society 156 (2009) C214.

[36] P. Antohi, D.A. Scherson, Theoretical aspects of impedance spectroscopy at a disk electrode embedded in an insulating plane: Reciprocity relationships, Electrochemical and Solid State Letters 11 (2008) F9. 